Published in final edited form as:

J Am Chem Soc. 2019 October 30; 141(43): 17305-17313. doi:10.1021/jacs.9b08801.

\title{
Controllable, Sequential, and Stereoselective C-H Allylic Alkylation of Alkenes
}

\author{
Ling Qin, Mohammed Sharique, Uttam K. Tambar ${ }^{\star}$ \\ Department of Biochemistry, The University of Texas Southwestern Medical Center, 5323 Harry \\ Hines Boulevard, Dallas, Texas 75390-9038, United States
}

\begin{abstract}
The direct conversion of $\mathrm{C}-\mathrm{H}$ bonds into new $\mathrm{C}-\mathrm{C}$ bonds represents a powerful approach to generate complex molecules from simple starting materials. However, a general and controllable method for the sequential conversion of a methyl group into a fully substituted carbon center remains a challenge. We report a new method for the selective and sequential replacement of three $\mathrm{C}-\mathrm{H}$ bonds at the allylic position of propylene and other simple terminal alkenes with different carbon groups derived from Grignard reagents. A copper catalyst and electron-rich biaryl phosphine ligand facilitate the formation of allylic alkylation products in high branch selectivity. We also present conditions for the generation of enantioenriched allylic alkylation products in the presence of catalytic copper and a chiral phosphine ligand. With this approach, diverse and complex products with substituted carbon centers can be generated from simple and abundant feedstock chemicals.
\end{abstract}

\section{Graphical Abstract}

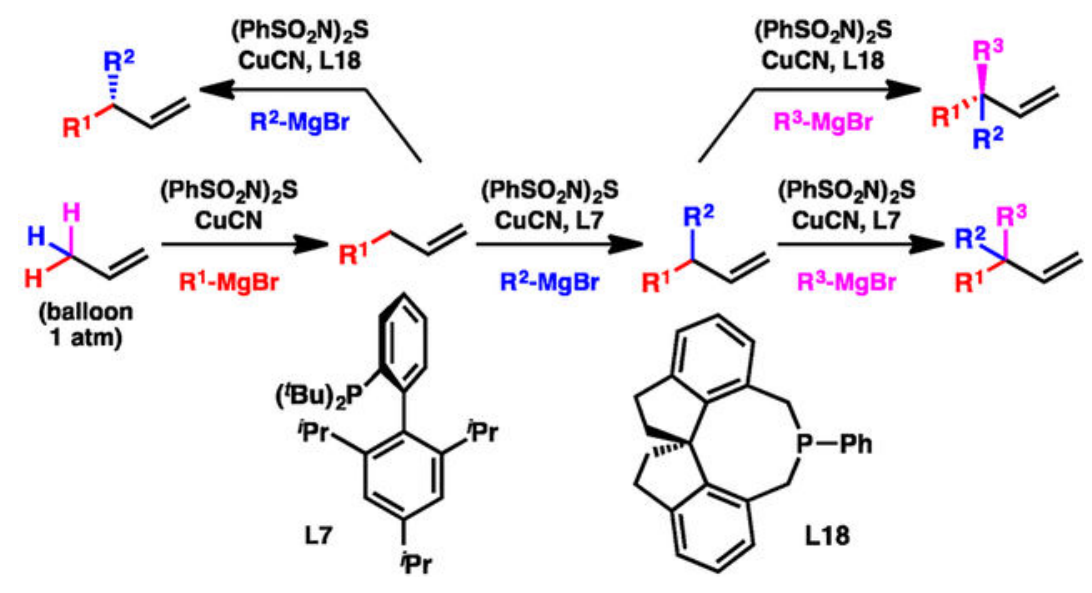

*Corresponding Author: Uttam.Tambar@utsouthwestern.edu.

Author Contributions

The manuscript was written through contributions of all authors. All authors have given approval to the final version of the manuscript.

Supporting Information

The Supporting Information is available free of charge on the ACS Publications website at DOI: 10.1021/jacs.9b08801.

Experimental procedures and characterization data (PDF)

The authors declare no competing financial interest. 


\section{INTRODUCTION}

The functionalization of $\mathrm{C}-\mathrm{H}$ bonds has emerged as a powerful and versatile strategy for the conversion of inexpensive and abundant starting materials into products of greater value. ${ }^{1} \mathrm{In}$ particular, the conversion of $\mathrm{C}-\mathrm{H}$ bonds into new $\mathrm{C}-\mathrm{C}$ bonds enables the rapid generation of complex molecules from simple substrates. ${ }^{2}$ Despite major advances in the field of selective $\mathrm{C}-\mathrm{H}$ alkylation, ${ }^{3}$ there are no general methods for the sequential conversion of a methyl group with three $\mathrm{C}-\mathrm{H}$ bonds into a fully substituted carbon center with three new $\mathrm{C}-\mathrm{C}$ bonds from three distinct carbon-based reagents (Figure 1A). The selective conversion of methyl groups into substituted carbon centers via controllable and sequential $\mathrm{C}-\mathrm{H}$ functionalization would enable the efficient synthesis of a broad range of products from simple starting materials.

Based on our group's research in selective $\mathrm{C}-\mathrm{H}$ allylic functionalization, ${ }^{4}$ we became interested in addressing the unsolved problem of sequential $\mathrm{C}-\mathrm{H}$ functionalization in the context of converting an allylic methyl group into a fully substituted allylic carbon center through three consecutive $\mathrm{C}-\mathrm{H}$ allylic alkylations with three different carbon-based reagents (Figure 1B). The major challenges in achieving this goal are threefold. First, a mode of activation must be identified that is reactive enough to undergo multiple $\mathrm{C}-\mathrm{H}$ functionalizations to generate a fully substituted carbon center. Second, each $\mathrm{C}-\mathrm{H}$ allylic alkylation must be selective for the formation of the branched product over the linear product, which becomes more sterically challenging over subsequent steps. Third, to generate $\mathrm{C}-\mathrm{C}$ bonds with three distinct carbon groups, the mode of activation must be controllable to avoid undesired over-functionalization of $\mathrm{C}-\mathrm{H}$ bonds in any step of the process. Elegant methods have been reported for the generation of fully substituted carbon centers via $\mathrm{C}-\mathrm{H}$ functionalization ${ }^{5}$ and for branch-selective $\mathrm{C}-\mathrm{H}$ allylic alkylation. ${ }^{6}$

However, these strategies are not amenable to the conversion of simple alkenes such as propylene into products with substituted allylic carbon centers via sequential $\mathrm{C}-\mathrm{H}$ allylic alkylation. While these reported strategies have overcome the challenges of reactivity and selectivity for the formation of fully substituted carbons, traditional $\mathrm{C}-\mathrm{H}$ functionalization and allylic alkylation approaches have not addressed the challenge of controllably forming distinct $\mathrm{C}-\mathrm{C}$ bonds.

Herein, we report the first general method to create a fully substituted carbon center at the allylic position of simple alkenes such as propylene. Our approach uniquely enables the selective and sequential replacement of three $\mathrm{C}-\mathrm{H}$ bonds with different carbon groups in a controllable fashion. The highly substituted terminal alkenes generated by this method are synthetically versatile precursors for many functional groups, including amines, alcohols, acids, epoxides, aldehydes, and internal alkenes. Therefore, we anticipate our method will provide a new strategy for converting simple alkenes into complex molecules with fully substituted carbons. 


\section{RESULTS AND DISCUSSION}

\section{Catalyst-Controlled Regioselectivity of Allylic Alkylation.}

A core feature of our controllable and sequential allylic alkylation strategy is the use of sulfur diimide reagent $\mathrm{PhSO}_{2} \mathrm{~N}=\mathrm{S}=\mathrm{NSO}_{2} \mathrm{Ph}$ (Table 1), ${ }^{7}$ which we hypothesized could serve the dual role of an electrophilic oxidant for the activation of alkenes (1 to 2) and a controllable leaving group in the subsequent copper-catalyzed alkylation with Grignard reagents.

We first examined the selective conversion of alkene 1 to branched allylic alkylation product 3 with a tertiary allylic carbon. To develop a branch-selective, controllable, and sequential allylic alkylation of alkene 1, we had to overcome the inherent preference of allylic sulfinamides such as 2 to undergo alkylation with Grignard reagents to selectively form linear products such as $4 .{ }^{4 \mathrm{~b}}$ Initially, we observed predominantly linear selectivity with various copper catalysts (entries 1-3). ${ }^{8}$ To our delight, $\mathrm{CuCN}$ reversed the regioselectivity of the reaction, and the desired branched product 3 was obtained as the major product with moderate 2.5:1 selectivity (entry 4). We observed an important solvent effect on the branch selectivity (entries 4-6). The use of $\mathrm{CH}_{2} \mathrm{Cl}_{2}$ as the primary solvent for allylic alkylations was beneficial for the branch selectivity of the reaction (entry 6). Based on detailed NMR studies by Gschwind and co-workers, ${ }^{9}$ we surmise that $\mathrm{CH}_{2} \mathrm{Cl}_{2}$ facilitates the formation of soluble monoalkyl cyanocuprates $(\mathrm{RCuCNMg})$ that favor the formation of branched allylic alkylation products, rather than insoluble copper-rich complexes or higher-order cuprates that would favor the formation of linear allylic alkylation products. As a practical advantage, solutions of Grignard reagents in $\mathrm{Et}_{2} \mathrm{O}$ were tolerated by the reaction without negatively impacting the yield or branch selectivity of the process, as long as $\mathrm{CH}_{2} \mathrm{Cl}_{2}$ remained the predominant solvent.

To further improve the regioselectivity of the allylic alkylation, we introduced various ligands for the copper catalyst (entries 7-13). Bipyridine L1 resulted in slightly higher regioselectivity of 10:1 (entry 7), while the more effective $\sigma$-donor triphenylphosphine $\mathbf{L 2}$ provided a 14:1 ratio (entry 8). Furthermore, the more electron-rich phosphine $\mathbf{L} 3$ improved regioselectivity (entry 9), whereas the more electron-poor phosphine $\mathbf{L} \mathbf{4}$ diminished regioselectivity (entry 10). Based on this trend in selectivity, we examined electron-rich biaryl phosphine ligands. ${ }^{10}$ CyJohnPhos $\mathbf{L} 5$ provided a regioselectivity of 13:1 in favor of branched product 3 (entry 11), which was similar to triphenylphosphine L2. Sterically hindered ligand L6 enhanced regioselectivity to 18:1 (entry 12). Ultimately, the bulkier $t$ BuXPhos $\mathbf{L} 7$ was identified as the optimal ligand, furnishing branched allylic product 3 in $>20: 1$ regioselectivity (entry 13). This class of ligands has found broad utility in controlling product selectivity of palladium-catalyzed reactions. Guided by these studies, we hypothesize that the electron-rich and bulky phosphine ligand $\mathbf{L} 7$ enhances the selectivity for the branched allylic alkylation by altering the relative rates of oxidative addition and reductive elimination en route to the desired product 3 (vide infra). Lowering the copper catalyst and ligand loading had a deleterious effect on the yield and regioselectivity (entry 14). Finally, we obtained the desired product 3 in 57\% isolated yield and $>20: 1$ regioselectivity with $10 \mathrm{~mol} \% \mathrm{CuCN}$ and $12 \mathrm{~mol} \%$ ligand $\mathbf{L} 7$ (entry 15). 
Other organometallic reagents were assayed in the allylic alkylation of 4-phenyl-1-butene (Figure 2). Under unoptimized conditions, we were pleased to observe that organolithium, organozinc, and organoaluminum reagents were compatible coupling partners for the $\mathrm{C}-\mathrm{H}$ allylic alkylation of terminal alkenes, with high selectivity for the branched product. Allylic sulfinamide intermediate 2 is presumably initially activated by nucleophilic Grignard reagent prior to oxidative addition with the copper catalyst (vide infra). Therefore, these alternative organometallic reagents may require further optimization to generate the desired product in synthetically useful yields.

\section{Allylic Alkylation of Propylene.}

We implemented our strategy for controllable and sequential construction of substituted carbon centers from simple alkenes by performing $\mathrm{C}-\mathrm{H}$ allylic alkylation of propylene, the simplest terminal alkene with available allylic $\mathrm{C}-\mathrm{H}$ bonds (Table 2). Since regioselectivity was not an issue in this allylic alkylation step, ligand $\mathbf{L} 7$ was not required. Diverse Grignard reagents, including aromatic (5a-e), benzylic $(\mathbf{5 f})$, alkyl $(\mathbf{5 g})$, and heteroatom-containing $(\mathbf{5 h}, \mathbf{5 l})$ reagents, provided high yields of allylic alkylation products. A methyl group $(\mathbf{5 c})$, electron-donating dimethylamino group (5d), and electron-withdrawing fluorine group (5e) were also well tolerated. Alkenes with hindered internal substituents, such as phenyl (5i-j) and tert-butyl groups (5k-l), furnished the desired product in high yield. Bromide Grignard reagents provided the product in higher yields than chloride Grignard reagents, presumably due to an undesirable Schlenk equilibrium with the latter reagents. ${ }^{11}$

\section{Allylic Alkylation of Terminal Alkenes to Products with Allylic Tertiary Carbons.}

Once we established the efficient conversion of propylene to a variety of alkenes, we explored the conversion of these products to terminal alkenes with allylic tertiary carbons. Commercially available 4-phenyl-1-butene was coupled with several Grignard reagents (Table 3). In the presence of $\mathbf{L} 7$, primary $(\mathbf{6 a}-\mathbf{h}, \mathbf{6} \mathbf{p})$, secondary cyclic $(\mathbf{6 i - k})$, acyclic (61, 6n, 6o), and tertiary (6m) Grignard reagents provided excellent yields and high regioselectivities for the desired branched products 6 . Grignard reagents with functional groups were also compatible with the reaction conditions, which allowed for the incorporation of an unsaturated chain (6q), silyl group (6r), and trifluoromethyl group (6s) into the products. Reaction with phenylmagnesium bromide resulted in the linear constitutional isomer $\mathbf{6 t}$ as the major product in poor regioselectivity (1:2 B:L), suggesting a modified reactivity of aryl-substituted allylcopper intermediates (vide infra).

Organomagnesium chlorides, bromides, and iodides were tolerated. The branch-selective allylic alkylation could be performed on a gram scale without affecting the efficiency and regioselectivity of the reaction $(\mathbf{6})$.

We also explored branch-selective allylic alkylation starting from a diverse range of terminal alkene substrates (Table 4). Benzylic (6u), aromatic (6v-x), cyclic (6y), and acyclic (6z) alkyl substitution in the starting material were tolerated, providing good yields and satisfying regioselectivities of products 6 . Electronically diverse phenyl rings $(\mathbf{6} \mathbf{v}-\mathbf{x})$ did not impact the efficiency of the reaction. A variety of functional groups were tolerated, including halides (6bb, $6 \mathbf{c c}, \mathbf{6 d d})$, protected alcohol (6ee), protected amine (6ff), thiophene (6aa), and Grignard-sensitive functional groups such as nitrile $(\mathbf{6 g g})$, ester $(\mathbf{6 h h})$, and 
epoxide (6ii). Interestingly, 1,1-disubstitued alkenes formed the desired branched product in moderate yields and excellent regioselectivities $(\mathbf{6 j j} \mathbf{j}, \mathbf{6 k k}, \mathbf{6} \mathbf{1 I})$. Under the reaction conditions, internal alkenes such as trans-5-decene did not yield any $\mathrm{C}-\mathrm{H}$ allylic alkylation product. Since we observed significant amounts of the ene-adduct of this internal alkene at 0 ${ }^{\circ} \mathrm{C}$, we conclude that the initial ene reaction with the sulfur diimide oxidant proceeded, but the subsequent reaction between the branched allylic sulfinamide and the Grignard reagent did not occur.

\section{Allylic Alkylation of Terminal Alkenes to Products with Allylic Quaternary Carbons.}

Next, we examined the conversion of already generated branched terminal alkenes 6 into products with fully substituted allylic carbon centers (7, Table 5). With 3,7-dimethyl-1octene as the standard substrate, reactions of primary $(\mathbf{7 a - c}, \mathbf{7 g}, \mathbf{h})$ and secondary $(\mathbf{7 d - f})$ Grignard reagents furnished the desired products. Despite the inherent difficulty of constructing congested fully substituted carbon centers via an allylic $\mathrm{C}-\mathrm{H}$ alkylation reaction, we obtained branched allylic alkylation products 7 in synthetically useful yields and regioselectivities with both primary and secondary Grignard reagents. Moreover, other 3,3-disubstituted alkenes, including a cyclic structure (7k) and a substrate with a primary chloride (7j), provided the desired product with high regioselectivity. The use of phenylmagnesium bromide resulted in diminished selectivity for the branched allylic arylation product $\mathbf{7 m}$. The inability to generate a product with two vicinal fully substituted carbon centers represents a current limitation to this chemistry $(\mathbf{7 n})$.

\section{Controllable and Sequential Allylic Alkylation of Propylene.}

To demonstrate the utility of this controllable and sequential strategy in assembling fully substituted carbon centers, we prepared several products by iterative introduction of three different carbon-based substituents at the allylic position of propylene (Table 6). Generally, excellent regioselectivity was maintained for the three-step sequence. Different functional groups could be introduced in each step, including an acetal (7p), thiophene (7q), and alkenyl group (7s). We anticipate this chemistry will provide a new approach to a broad diversity and complexity of products with fully substituted carbon centers that can be generated from simple, abundant feedstock chemicals such as propylene.

\section{Proposed Mechanism.}

We propose a mechanism that accounts for the high regioselectivity in the formation of the branched products in the allylic alkylation step (Figure 3). Initial oxidation of the alkene substrate yields ene adduct 9, which is activated by the Grignard reagent to furnish allylic sulfimine 10. For heterocuprates such as $\left[\mathrm{R}^{3} \mathrm{Cu}^{\mathrm{I}} \mathrm{CNL}_{7}\right] \mathrm{MgBr}$, oxidative addition of the $\mathrm{Cu}^{\mathrm{I}}$ complex to the allylic substrate dictates the regioselectivity of the allylic substitution. ${ }^{12,13}$ Therefore, either allylic sulfimine 10 forms $\mathrm{Cu}^{\mathrm{III}}$-allyl complex 12 via transition state 11 , with ligand $\mathbf{L} 7$ on the $\mathrm{C} 1$ side of the allyl system, to yield product 7, or allylic sulfimine 10 forms $\mathrm{Cu}^{\mathrm{III}}$-allyl complex 14 via transition state 13 , with ligand $\mathbf{L} 7$ on the $\mathrm{C} 3$ side, to give product 8 . We propose a preference for transition state 11 with improved FMO interactions between the HOMO of the organocuprate and the LUMO of allylic sulfimine 10. Transition state 11 leads to conformationally stable enyl $[\sigma+\pi]$-allylcopper-(III) complex 12 , in which 
the copper atom is $\sigma$-bonded to $\mathrm{C} 3$. Subsequent reductive elimination furnishes branched product 7. To account for the enhanced regioselectivity and preference for transition state 11 in the presence of ligand $\mathbf{L} 7$, we propose that the electron-rich phosphine stabilizes transition state 11 for oxidative addition. In addition, the bulky tert-butyl groups on phosphorus and isopropyl substituents on the aromatic ring of ligand $\mathbf{L} 7$ promote reductive elimination of enyl $[\sigma+\pi]$-allylcopper(III) complex 12 before isomerization can occur to the enyl $[\sigma+\pi]$-allylcopper(III) complex 14, which would lead to the undesired linear product 8 . We surmise that excess Grignard reagent is required to obtain synthetically useful yields of product because of multiple roles for the Grignard reagent in the transformation. One equivalent of Grignard is consumed in the conversion of allylic sulfinamide 9 to allylic sulfimine 10, and another equivalent is ultimately transferred to the product in the allylic alkylation step. Additional Grignard reagent may be required in the decomposition of the sulfur-containing leaving group into a thioether. ${ }^{4 b, 14}$

\section{Enantioselective Allylic Alkylation.}

Given the importance of achiral phosphine $\mathbf{L} 7$ for branch selectivity in the $\mathrm{C}-\mathrm{H}$ allylic alkylation process, we hypothesized that the proper choice of a chiral phosphine ligand could facilitate the formation of enantioenriched terminal alkenes with allylic stereogenic centers (Table 7). Allylic sulfinamide 2 was generated from 4-phenylbutene, isolated, and then treated with catalytic $\mathrm{CuCN}$ and chiral ligands in $\mathrm{CH}_{2} \mathrm{Cl}_{2}$ at $-78^{\circ} \mathrm{C}$. Upon addition of $i-\mathrm{BuMgBr}$, the reaction mixture was warmed to $0{ }^{\circ} \mathrm{C}$ and stirred. We initially examined a broad range of chiral ligands, including bidentate phosphines L8-L12 (entries 1-5). Although selectivity for the branched product 3 was maintained across this diverse set of ligands, the allylic alkylation product was consistently generated with low levels of enantioselectivity. P,N ligand L13, phosphite L14, and phosphinite $\mathbf{L 1 5}$ all furnished product 3 as essentially a racemate (entries 6-8). Finally, we examined a series of chiral monodentate phosphines. Whereas ligands $\mathbf{L 1 6}$ and $\mathbf{L 1 7}$ provided the allylic alkylation product in negligible levels of enantioselectivity (entries 9, 10), phosphine $\mathbf{L 1 8}$ yielded product 3 in 82\% yield, >20:1 regioselectivity, and 78:22 er (entry 11). Given the high selectivity for the branched product with ligand $\mathbf{L 1 8}$, we surmised that a broad range of reaction media would retain the high regioselectivity with the potential to improve the enantioselectivity. In ethereal solvent, product 3 was formed in reasonable regioselectivity but with diminished yield and enantioselectivity (entry 12). Aromatic solvents, such as toluene, furnished the desired product in high yield and regioselectivity with an improved enantiomeric ratio of $84: 16$ (entry 13). Gratifyingly, by initiating the reaction at $-78{ }^{\circ} \mathrm{C}$ and warming it up to $-30^{\circ} \mathrm{C}$, we obtained the branched allylic alkylation product 3 in $86 \%$ isolated yield, >20:1 regioselectivity, and 94:6 er (entry 14).

With the identification of optimal conditions for the catalytic enantioselective branchselective allylic alkylation, we examined the scope of this transformation with other terminal alkenes and Grignard reagents (Table 8). 4-Phenylbutene coupled with primary Grignard reagents $(\mathbf{6 b}, \mathbf{6 d}, \mathbf{6 g}, \mathbf{6}, \mathbf{6}, \mathbf{v})$ as well as secondary cyclic and acyclic Grignard reagents $(\mathbf{6} \mathbf{i}$, $\mathbf{6 k}, \mathbf{6} \mathbf{1})$. Other functionalized terminal alkenes were also compatible with the reaction, including a substrate with a remote heteroaromatic ring (6aa) and an unsaturated sulfonamide (6ff). 
Preliminary studies with chiral ligands for the copper-catalyzed branch-selective allylic alkylation suggest that our method affords us the opportunity to transform simple terminal alkenes into enantioenriched alkenes (Figure 4). Conversion of 4-phenylbutene to allylic sulfinamide 2 followed by subjection to the $\mathrm{CuCN/L7} \mathrm{conditions} \mathrm{for} \mathrm{branch-selective} \mathrm{allylic}$ alkylation furnished racemic products $\mathbf{6 b}$ and $\mathbf{6 1}$. These two unsaturated hydrocarbons were then treated with the sulfur diimide oxidant to yield allylic sulfinamides $\mathbf{1 5}$ and $\mathbf{1 6 .}$

Treatment with the CuCN/L18 reaction conditions furnished enantioenriched alkenes $\mathbf{7 l}$ and 17 with fully substituted allylic stereogenic centers. The lower enantioselectivity in forming the products with quaternary stereogenic centers compared to tertiary stereogenic centers may be due to the formation of trisubstituted allylic sulfinamides $\mathbf{1 5}$ and $\mathbf{1 6}$ as mixtures of $E / Z$ isomers. We are currently examining catalyst-controlled methods for generating trisubstituted allylic sulfinamides in high selectivity for the $E$-alkene isomer.

\section{CONCLUSION}

In conclusion, we have developed a general method for converting multiple $\mathrm{C}-\mathrm{H}$ bonds to $\mathrm{C}-\mathrm{C}$ bonds via a ligand-controlled copper-catalyzed controllable and sequential allylic alkylation of alkenes. We demonstrated the formation of substituted carbon centers at the allylic position of simple terminal alkenes, including propylene, which provides efficient and flexible access to a diverse range of products. We proposed a mechanism that accounts for the catalyst and ligand control of branch selectivity in product formation. We also discovered conditions to generate enantioenriched allylic alkylation products in the presence of catalytic copper and chiral phosphine $\mathbf{L 1 8}$.

Our method represents a new chemical strategy for converting simple terminal alkene substrates into complex unsaturated products in synthetically useful yields, regioselectivities, and enantioselectivities. Importantly, the products generated by this method may also be accessed in theory with high regioselectivity and enantioselectivity through the catalytic allylic substitution of prefunctionalized allyl electrophiles with organometallic reagents. ${ }^{15}$ Our approach and the traditional allylic substitution of allyl electrophiles have complementary strengths and weaknesses. ${ }^{15}$ In some cases, we anticipate that the allylic substitution of prefunctionalized allyl halides, acetates, carbonates, or phosphates will be preferential. For example, while both strategies are compatible with organomagnesium, organolithium, organozinc, and organoaluminum reagents, in some cases the allylic substitution of preformed allylic electrophiles can be performed with organoborane reagents, including alkynyl boron reagents. In addition, currently the branched allylic arylation product with aryl nucleophiles cannot be accessed with our method. In other instances, we anticipate that our controllable and sequential strategy for allylic alkylation will be preferential. For some classes of substrates the selective synthesis of the prefunctionalized allyl electrophile may be challenging, whereas the unfunctionalized terminal alkene substrate will be readily accessible. Moreover, a sequential allylic alkylation with the traditional approach with two or three carbon-based nucleophiles would require multiple intermediary steps to generate the desired allylic electrophile for each round of alkylation, whereas our approach enables the sequential addition of carbon substituents in one pot for each step. Ultimately, the existence of two complementary strategies for regioselective and enantioselective allylic alkylation will be beneficial to the synthetic community. 


\section{Supplementary Material}

Refer to Web version on PubMed Central for supplementary material.

\section{ACKNOWLEDGMENTS}

Financial support was provided by the W. W. Caruth, Jr. Endowed Scholarship, Welch Foundation (I-1748), National Institutes of Health (R01GM102604), American Chemical Society Petroleum Research Fund (59177ND1), Teva Pharmaceuticals Marc A. Goshko Memorial Grant (60011-TEV), and Sloan Research Fellowship.

\section{REFERENCES}

(1). (a)Labinger JA; Bercaw JE Understanding and exploiting C-H bond activation. Nature 2002, 417, 507-514. [PubMed: 12037558] (b)Bergman RG Organometallic chemistry: C-H activation. Nature 2007, 446, 391-393. [PubMed: 17377575] (c)Grennberg H; Bäckvall J-E, Allylic Oxidations In Transition Metals for Organic Synthesis; Wiley-VCH Verlag GmbH, 2008; pp 243-265.(d)Liu G; Wu Y Palladium-Catalyzed Allylic C-H Bond Functionalization of Olefins In C-H Activation; Yu J-Q, Shi Z, Eds.; Springer: Berlin, Heidelberg, 2010; pp 195-209.(e)Andrus MB Allylic and Benzylic Oxidation In Stereoselective Synthesis 3; 1st ed.; Evans PA, Ed.; Georg Thieme Verlag: Stuttgart, 2011; Vol. 3.(f)Engle KM; Mei T-S; Wasa M; Yu J-Q Weak Coordination as a Powerful Means for Developing Broadly Useful C-H Functionalization Reactions. Acc. Chem. Res 2012, 45, 788-802. [PubMed: 22166158] (g)Newhouse T; Baran PS If C-H Bonds Could Talk: Selective C-H Bond Oxidation. Angew. Chem., Int. Ed 2011, 50, 3362-3374.(h)White MC Adding Aliphatic C-H Bond Oxidations to Synthesis. Science 2012, 335, 807-809. [PubMed: 22344434] (i)Gensch T; Hopkinson MN; Glorius F; Wencel-Delord J Mild metal-catalyzed C-H activation: examples and concepts. Chem. Soc. Rev 2016, 45, 2900 2936. [PubMed: 27072661] (j)He J; Wasa M; Chan KSL; Shao Q; Yu J-Q Palladium-Catalyzed Transformations of Alkyl C-H Bonds. Chem. Rev 2017, 117, 8754-8786. [PubMed: 28697604] (k)Chu JCK; Rovis T Complementary Strategies for Directed C(sp3)-H Functionalization: A Comparison of Transition-Metal-Catalyzed Activation, Hydrogen Atom Transfer, and Carbene/ Nitrene Transfer. Angew. Chem., Int. Ed 2018, 57, 62-101.

(2). (a)Jensen T; Fristrup P Toward Efficient Palladium-Catalyzed Allylic C-H Alkylation. Chem. Eur. J 2009, 15, 9632-9636. [PubMed: 19718728] (b)Dong Z; Ren Z; Thompson SJ; Xu Y; Dong G Transition-Metal-Catalyzed C-H Alkylation Using Alkenes. Chem. Rev 2017, 117, 93339403. [PubMed: 28125210]

(3). (a)He J; Li S; Deng Y; Fu H; Laforteza BN; Spangler JE; Homs A; Yu J-Q Ligand-Controlled C(sp3)-H Arylation and Olefination in Synthesis of Unnatural Chiral $\boldsymbol{a}$-Amino Acids. Science 2014, 343, 1216-1220. [PubMed: 24626923] (b)Chen G; Shigenari T; Jain P; Zhang Z; Jin Z; He J; Li S; Mapelli C; Miller MM; Poss MA; Scola PM; Yeung K-S; Yu J-Q Ligand-Enabled $\beta$-C-H Arylation of $a$-Amino Acids Using a Simple and Practical Auxiliary. J. Am. Chem. Soc 2015, 137, 3338-3351. [PubMed: 25697780]

(4). (a)Bao H; Tambar UK Catalytic Enantioselective Allylic Amination of Unactivated Terminal Olefins via an Ene Reaction/[2,3]-Rearrangement. J. Am. Chem. Soc 2012, 134, 18495-18498. [PubMed: 23106555] (b)Bao H; Bayeh L; Tambar UK Allylic Functionalization of Unactivated Olefins with Grignard Reagents. Angew. Chem., Int. Ed 2014, 53, 1664-1668.(c)Bayeh L; Le PQ; Tambar UK Catalytic allylic oxidation of internal alkenes to a multifunctional chiral building block. Nature 2017, 547, 196-200. [PubMed: 28636605]

(5). (a)Fuji K Asymmetric Creation of Quaternary Carbon Centers. Chem. Rev 1993, 93, 2037-2066. (b)Christoffers J; Mann A Enantioselective Construction of Quaternary Stereocenters. Angew. Chem., Int. Ed 2001, 40, 4591-4597.(c)Quasdorf KW; Overman LE Catalytic Enantioselective Synthesis ofQuaternary Carbon Stereocenters. Nature 2014, 516, 181. [PubMed: 25503231] (d)Zeng X-P; Cao Z-Y; Wang Y-H; Zhou F; Zhou J Catalytic Enantioselective Desymmetrization Reactions to All-Carbon Quaternary Stereocenters. Chem. Rev 2016, 116, 7330-7396. [PubMed: 27251100]

(6). (a)Fujita K; Yorimitsu H; Shinokubo H; Oshima K Transformation of Zirconocene-Olefin Complexes into Zirconocene Allyl Hydride and Their Use as Dual NucleophilicReagents: 
Reactions with Acid Chloride and 1,4-Diketone. J. Am. Chem. Soc 2004, 126, 6776-6783. [PubMed: 15161306] (b)Tao Z-L; Li X-H; Han Z-Y; Gong L-Z Diastereoselective Carbonyl Allylation with Simple Olefins Enabled by Palladium Complex-Catalyzed C-H Oxidative Borylation. J. Am. Chem. Soc 2015, 137, 4054-4057. [PubMed: 25754467]

(7). (a)Sharpless KB; Hori T Allylic Amination of Olefins and Acetylenes by Imido Sulfur Compounds. J. Org. Chem 1976, 41, 176-177.(b)Sharpless KB; Hori T; Truesdale LK; Dietrich CO Allylic Amination of Olefins and Acetylenes by Imido Selenium Compounds. J. Am. Chem. Soc 1976, 98, 269-271.(c)Kresze G; Muensterer H Bis(methoxycarbonyl)sulfur Diimide, AConvenient Reagent for the Allylic Amination of Alkenes. J. Org. Chem 1983, 48, 3561-3564. (d)Katz TJ; Shi S A Simple Allylic Amination Procedure and the Metathesis of NSulfinylcarbamates. J. Org. Chem 1994, 59, 8297-8298.

(8). See the Supporting Information for a more comprehensive discussion of optimization studies.

(9). Neumeier M; Gschwind RM Elongated Gilman Cuprates: The Key to Different Reactivities of Cyano- and Iodocuprates. J. Am. Chem. Soc 2014, 136, 5765-5772. [PubMed: 24660892]

(10). (a)Surry DS; Buchwald SL BiarylPhosphane Ligands in Palladium-CatalyzedAmination. Angew. Chem., Int. Ed 2008, 47, 6338-6361.(b)Martin R; Buchwald SL Palladium-Catalyzed SuzukiMiyaura Cross-Coupling Reactions Employing Dialkylbiaryl-Phosphine Ligands. Acc. Chem. Res 2008, 41, 1461-1473. [PubMed: 18620434]

(11). (a)Schlenk W; Wilh SÜber die Konstitution der Grignardschen Magnesiumverbindungen. Ber. Dtsch. Chem. Ges. B 1929, 62, 920-924.(b)Neufeld R; Teuteberg TL; Herbst-Irmer R; Mata RA; Stalke D Solution Structuresof Hauser Base iPr2 $\mathrm{NMgCl}$ and Turbo-Hauser Base iPr2 $\mathrm{NMgCl} \cdot \mathrm{LiCl}$ in THF andtheInfluenceofLiCl on theSchlenk-Equilibrium. J. Am. Chem. Soc 2016, 138, 4796-4806. [PubMed: 27011251]

(12). Yoshikai N; Zhang S-L; Nakamura E Origin of the Regio- and Stereoselectivity of Allylic Substitution of Organocopper Reagents. J. Am. Chem. Soc 2008, 130, 12862-12863. [PubMed: 18763774]

(13). Yoshikai N; Nakamura E Mechanisms of Nucleophilic Organocopper(I) Reactions. Chem. Rev 2012, 112 (4), 2339-2372. [PubMed: 22111574]

(14). (a)Harpp DN; Vines SM; Montillier JP; Chan TH Organic sulfur chemistry. Part XXII. The reaction of sulfinate esters with Grignard and organocopper lithium reagents. A useful route to chiral sulfoxides. J. Org. Chem 1976, 41, 3987-3992.(b)Gendreau Y; Normant JF; Villieras J Reaction of Organomagnesium with Allylic Sulfides and Sulfonium Salts Catalyzed by CopperSalts. J. Organomet. Chem 1977, 142, 1-7.(c)Julia M; Righini A; Verpeaux J-N Couplage des sulfones allyliques avec des reactifs de grignarden presence de cuivresynthesed'olefines. Tetrahedron Lett. 1979, 20, 2393-2396.(d)Masaki Y; Sakuma K; Kaji K Regio-Selective and Stereo-Selective Gamma-Substitution of Allylic Sulfoxides and Sulfones with Lithium Dialkylcuprates - A New Synthesis of Trisubstituted Olefins. J. Chem. Soc., Chem. Commun 1980, 434-435.(e)Deleris G; Dunogues J; Gadras A Alkylation de terpenes en deux etapes par enereaction. Tetrahedron Lett. 1984, 25, 2135-2138.

(15). For reviews, see:(a)Trost BM; Van Vranken DL Asymmetric Transition Metal-Catalyzed Allylic Alkylations. Chem. Rev 1996, 96, 395-422. [PubMed: 11848758] (b)Moberg C; Bremberg U; Hallman K; Svensson M; Norrby P-O; Hallberg A; Larhed M; Csoregh I Selectivity and reactivity in asymmetric allylic alkylation. Pure Appl. Chem 1999, 71, 1477-1483.(c)Trost BM; Lee C In Asymmetric Allylic Alkylation Reactions; Wiley-VCH, 2000; pp 593-649.(d)Kazmaier U Palladium catalyzed allylic alkylations of nonstabilized enolates. Curr. Org. Chem 2003, 7, 317-328.(e)Trost BM; Crawley ML Asymmetric Transition-Metal-Catalyzed Allylic Alkylations: Applications in Total Synthesis. Chem. Rev 2003, 103, 2921-2943. [PubMed: 12914486] (f)Helmchen G; Ernst M; Paradies G Application of allylic substitutions in natural products synthesis. Pure Appl. Chem 2004, 76, 495-506.(g)Miyabe H; Takemoto Y Regio- and stereocontrolled palladium- or iridium-catalyzed allylation. Synlett 2005, 1641-1655. (h)Nishibayashi Y; Uemura S In C-C Bond Formation (part 2) by Substitution Reactions: Allylic Alkylation; Elsevier Ltd., 2007; pp 75-122.(i)Falciola CA; Alexakis A Copper-catalyzed asymmetric allylic alkylation. Eur. J. Org. Chem 2008, 2008 (22), 3765-3780.(j)Harutyunyan SR; den Hartog T; Geurts K; Minnaard AJ; Feringa BL Catalytic Asymmetric Conjugate Addition and Allylic Alkylation with Grignard reagents. Chem. Rev 2008, 108, 2824-2852. [PubMed: 18698733] (k)Mori M In C-C Bond Formation by Metal-Catalyzed Asymmetric 
Allylic Alkylation; Elsevier B.V., 2012; pp 74-99.(1)Hong AY; Stoltz BM The Construction of All-Carbon Quaternary Stereocenters by Use of Pd-Catalyzed Asymmetric Allylic Alkylation Reactions in Total Synthesis. Eur. J. Org. Chem 2013, 2013, 2745-2759.(m)Tissot M; Li H; Alexakis A In Copper-Catalyzed Asymmetric Conjugate Addition and Allylic Substitution of Organometallic Reagents to Extended Multiple-Bond Systems; Wiley-VCH Verlag GmbH \& Co. KGaA, 2014; pp 69-84.(n)Liu Y; Han S-J; Liu W-B; Stoltz BM Catalytic Enantioselective Construction of Quaternary Stereocenters: Assembly of Key Building Blocks for the Synthesis of Biologically Active Molecules. Acc. Chem. Res 2015, 48, 740-751. [PubMed: 25715056] (o)Trost BM Metal catalyzed allylic alkylation: its development in the Trost laboratories. Tetrahedron 2015, 71, 5708-5733. [PubMed: 26236048] (p)Hethcox JC; Shockley SE; Stoltz BM Iridium-Catalyzed Diastereo-, Enantio-, and Regioselective Allylic Alkylation with Prochiral Enolates. ACS Catal. 2016, 6, 6207-6213. [PubMed: 28649462] (q)Hornillos V; Gualtierotti J-B; Feringa BL Asymmetric allylic substitutions using organometallic reagents. Top. Organomet. Chem 2016, 58, 1-39 Progress in Enantioselective Cu(I)- Catalyzed Formation of Stereogenic Centers.(r)Qu J; Helmchen G Applications of Iridium-Catalyzed Asymmetric Allylic Substitution Reactions in Target-Oriented Synthesis. Acc. Chem. Res 2017, 50, 2539-2555. [PubMed: 28937739] (s)Shockley SE; Hethcox JC; Stoltz BM Intermolecular Stereoselective IridiumCatalyzed Allylic Alkylation: An Evolutionary Account. Synlett 2018, 29, 2481-2492. [PubMed: 31754289] (t)Trost BM; Schultz JE Palladium-Catalyzed Asymmetric Allylic Alkylation Strategies for the Synthesis of Acyclic Tetrasubstituted Stereocenters. Synthesis 2019, 51, 1-30. 
A Unsolved Problem of Controllable and Sequential Multiple $\boldsymbol{C}-\boldsymbol{H}$ Alkylations at a Single Carbon Atom

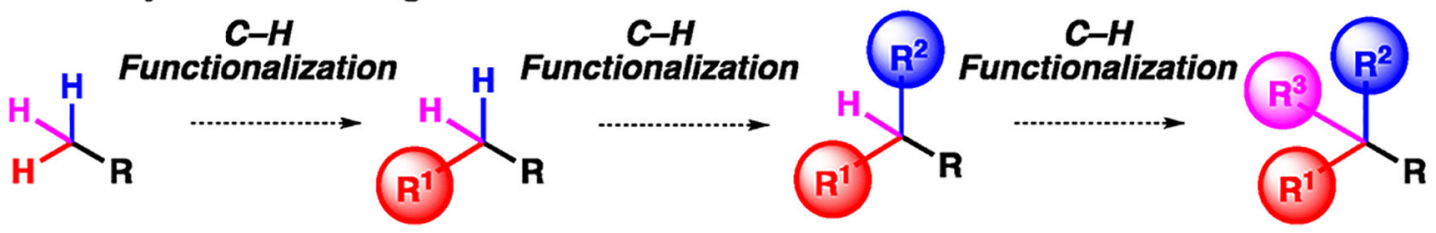

B Our Approach to the Controllable and Sequential Allylic C-H Alkylation of Terminal Alkenes (This Research)
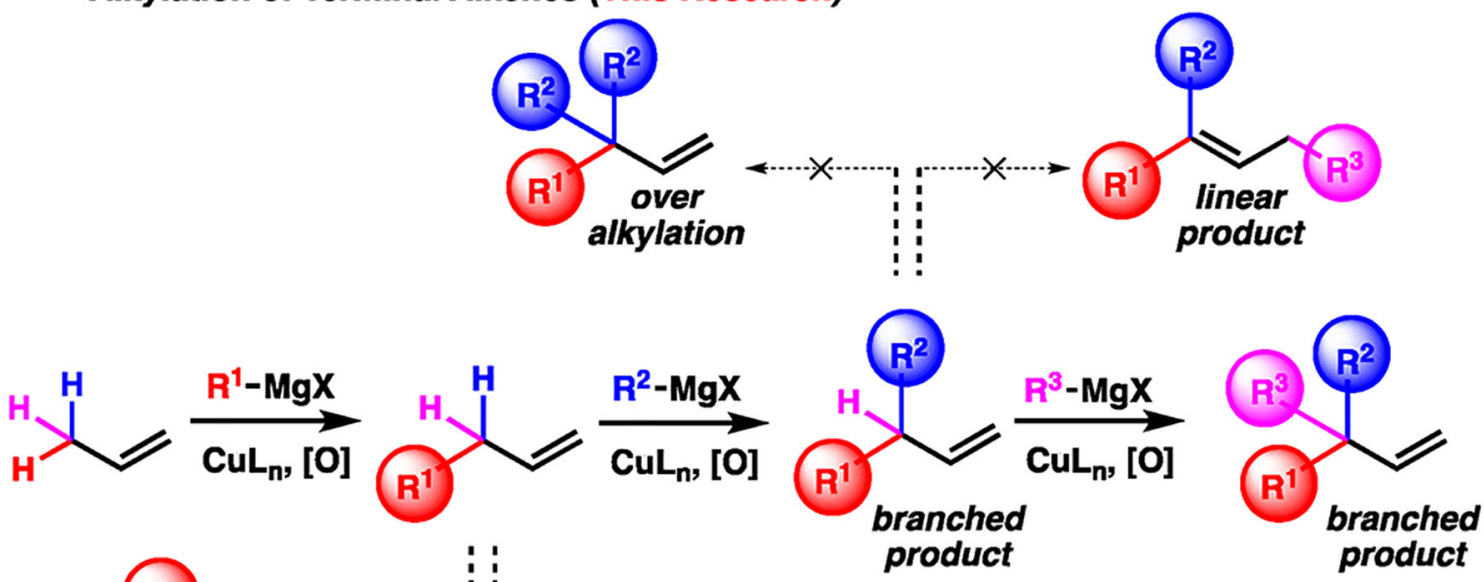

Figure 1.

Controllable and sequential C-H alkylation. 


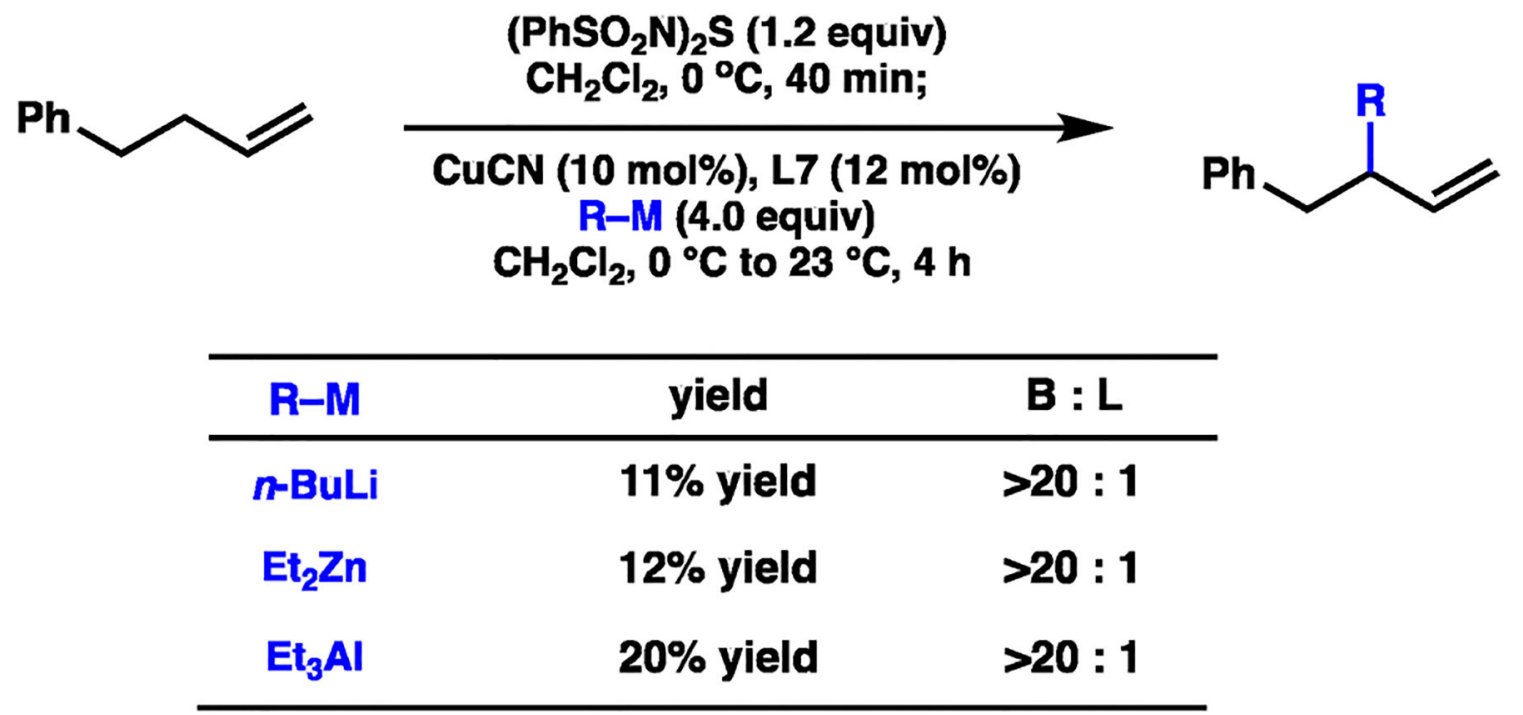

Figure 2.

Branch-selective $\mathrm{C}-\mathrm{H}$ allylic alkylation of 4-phenyl-1-butene with other organometallic reagents. 


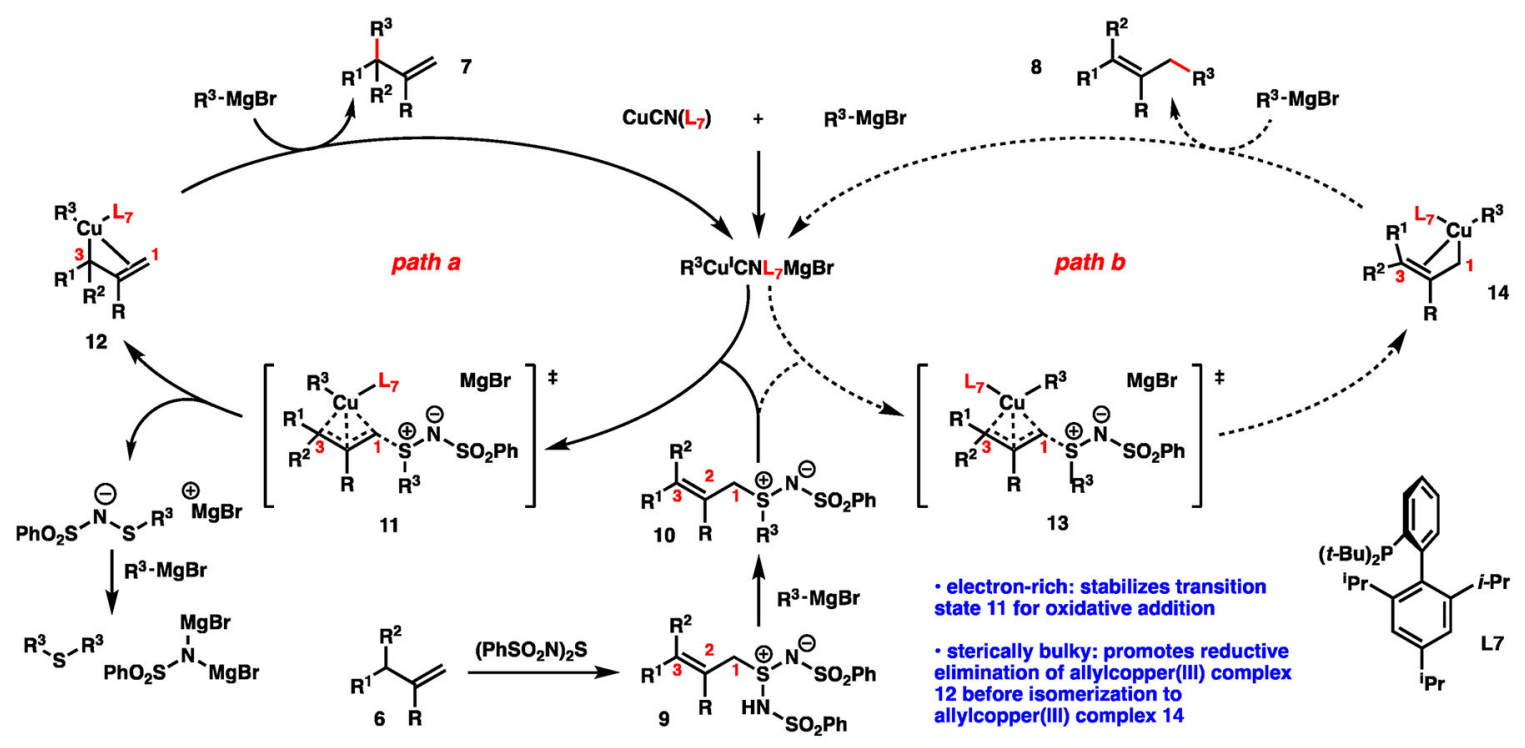

Figure 3.

Proposed mechanism of ligand-controlled branch-selective allylic alkylation of terminal alkenes. 

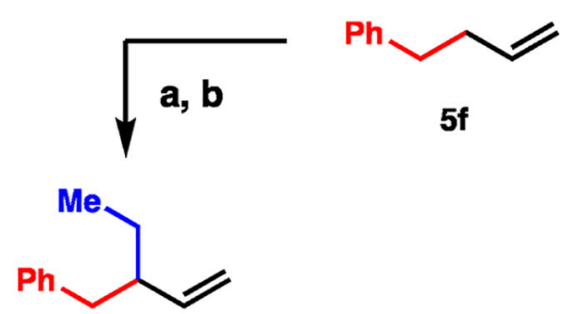

$6 b, 57 \%$ yield
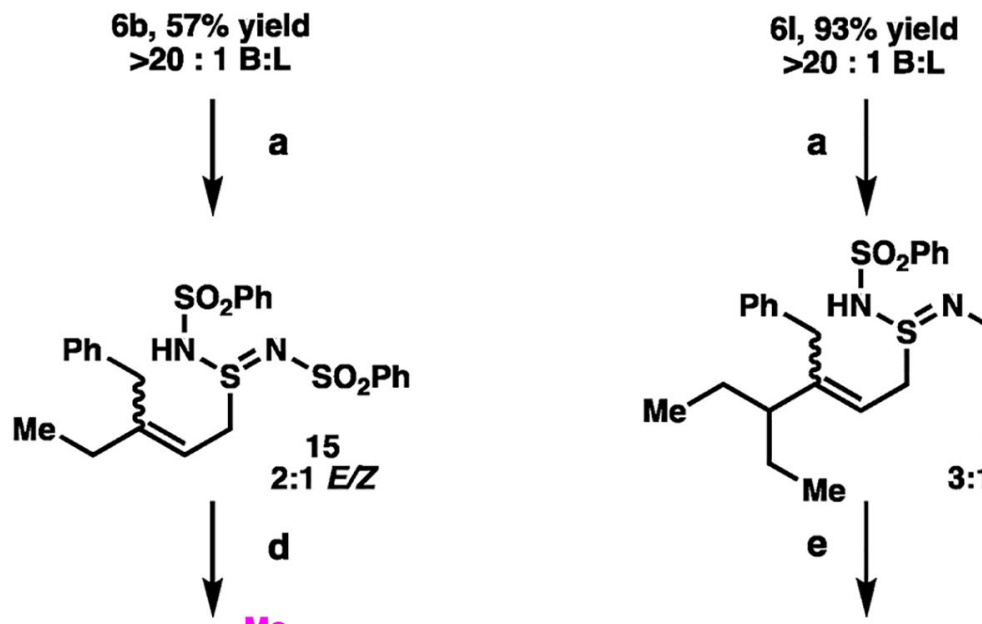<smiles>C=CC(CC)(Cc1ccccc1)CC(C)C</smiles><smiles>CCC(=CC[SH](Cc1ccccc1)N=S(=O)(Oc1ccccc1)c1ccccc1)C(CC)CC</smiles>

$71,51 \%$ yield $>20: 1 \mathrm{~B}: \mathrm{L}$ $63: 37$ er<smiles>C=C[C@](C)(Cc1ccccc1)C(CC)CC</smiles>

$$
\begin{gathered}
17,66 \% \text { yield } \\
6: 1 \mathrm{~B}: \mathrm{L} \\
65: 35 \mathrm{er}
\end{gathered}
$$

Reaction Conditions:

a. $\left(\mathrm{PhSO}_{2} \mathrm{~N}\right)_{2} \mathrm{~S}$ (1.2 equiv), $\mathrm{Et}_{2} \mathrm{O}, 4^{\circ} \mathrm{C}$

b. CuCN (10 mol\%), $\mathrm{L7}$ (12 mol\%), Et-MgBr (4.0 equiv), $\mathrm{CH}_{2} \mathrm{Cl}_{2}, 0^{\circ} \mathrm{C}$ to $23^{\circ} \mathrm{C}$ c. CuCN (10 mol\%), L7 (12 mol\%), ${ }^{s} \mathrm{Bu}-\mathrm{MgBr}$ (4.0 equiv), $\mathrm{CH}_{2} \mathrm{Cl}_{2}, 0^{\circ} \mathrm{C}$ to $23^{\circ} \mathrm{C}$ d. CuCN (10 mol\%), L18 (24 mol\%), $i-\mathrm{Pr}-\mathrm{MgBr}$ (4 equiv), PhMe, $-78{ }^{\circ} \mathrm{C}$ to $-30^{\circ} \mathrm{C}$ e. CuCN (10 mol\%), L18 (24 mol\%), Me-MgBr (4 equiv), PhMe, $-78{ }^{\circ} \mathrm{C}$ to $-30^{\circ} \mathrm{C}$

Figure 4.

Synthesis of enantioenriched alkenes with either tertiary or quaternary allylic stereogenic centers. B:L is branched:linear allylic alkylation products. 
Table 1.

Optimization of Ligand-Controlled Branch-Selective Allylic Alkylation of Terminal Alkenes ${ }^{g}$

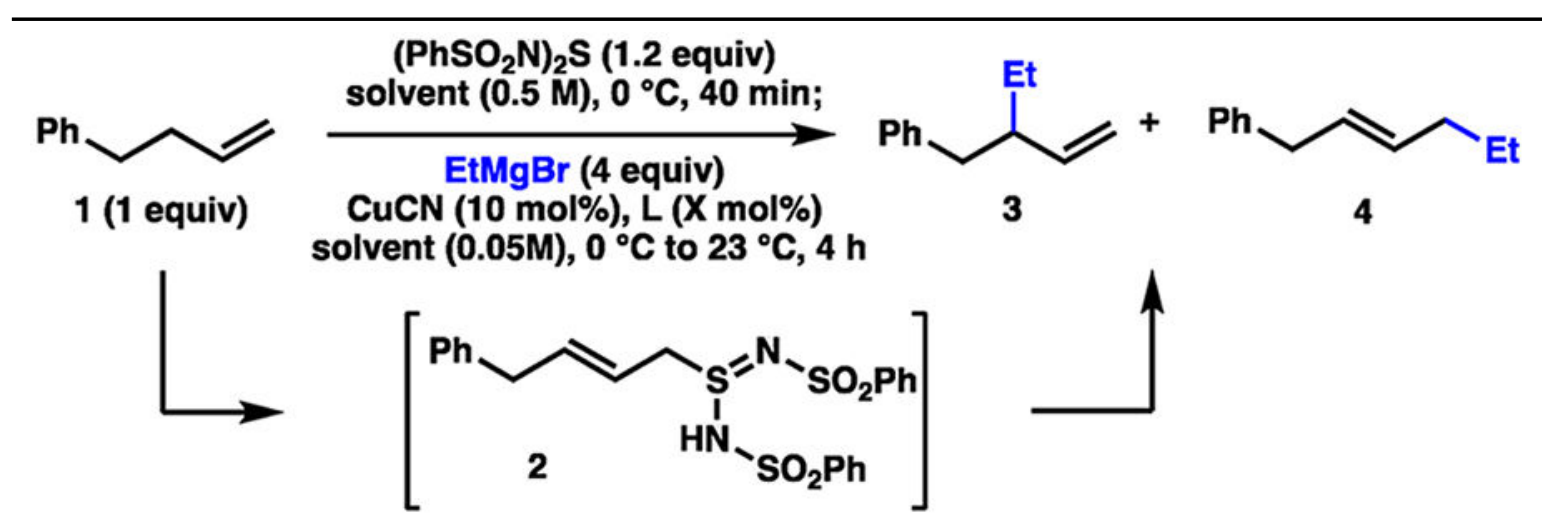

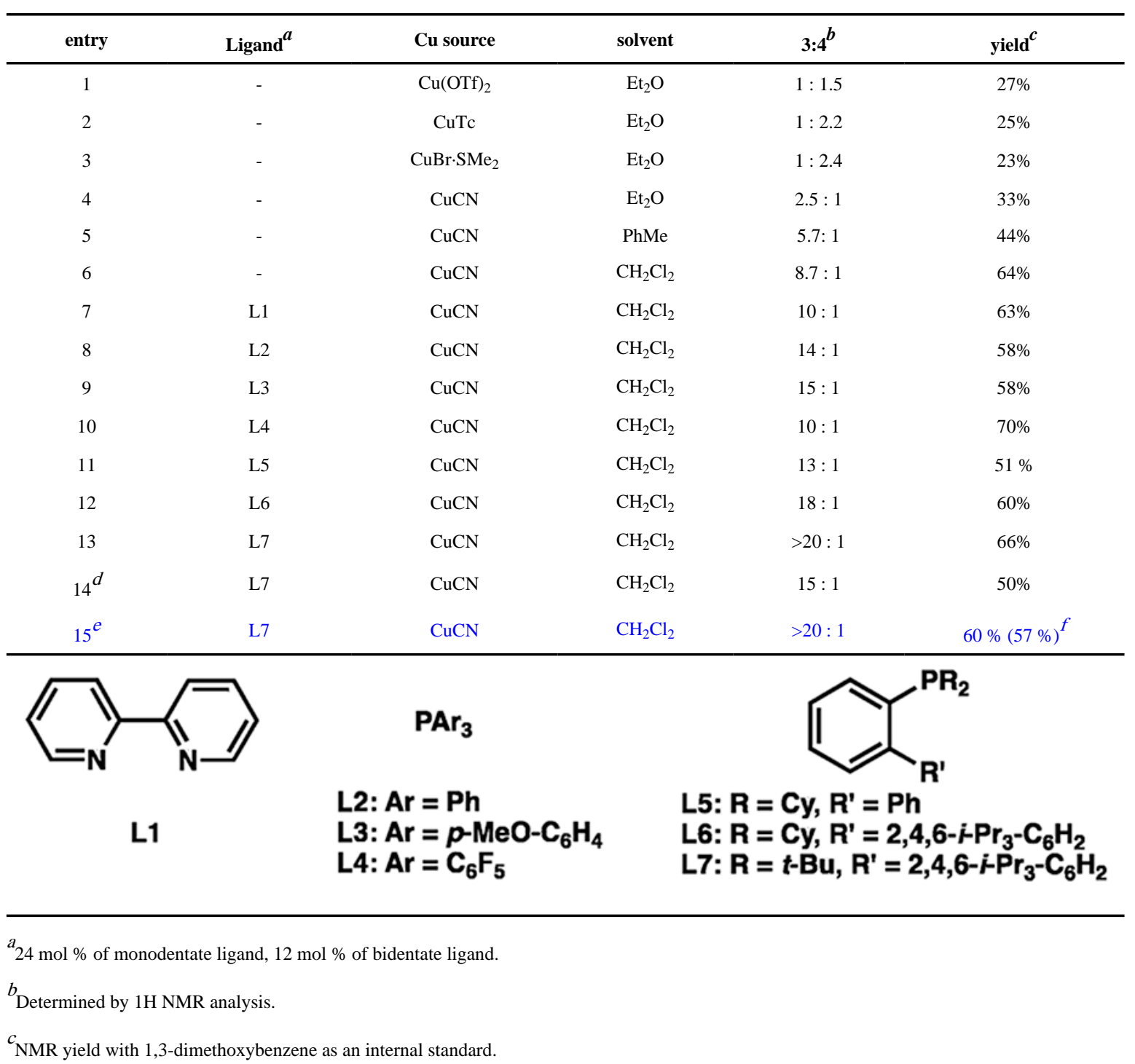


$d_{5 \mathrm{~mol}} \% \mathrm{CuCN}$ and $6 \mathrm{~mol} \%$ ligand.

$e_{10 \mathrm{~mol}} \% \mathrm{CuCN}$ and $12 \mathrm{~mol} \%$ ligand.

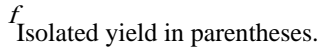

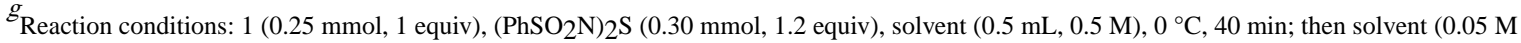
by dilution), Cu source (10 mol \%), ligand (12 or $24 \mathrm{~mol} \%$ ), EtMgBr ( $3 \mathrm{M}$ in Et2O, 4 equiv), 0 to $23{ }^{\circ} \mathrm{C}, 4 \mathrm{~h}$. 
Table 2.

Allylic Monofunctionalization of Propylene and Other 2-Substituted Alkenes ${ }^{a}$

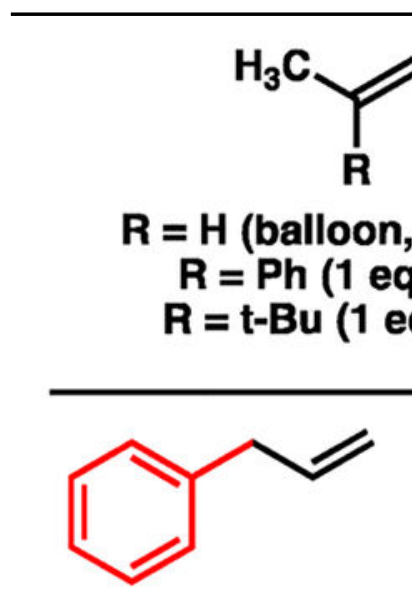

$5 a, 82 \%$ yield<smiles>C=CCc1ccc(F)cc1</smiles>

5 e, $80 \%$ yield<smiles>C=CCc1ccc(-c2ccccc2)cc1</smiles>

5b, $90 \%$ yield

Ph

$\mathbf{5 f}, \mathbf{5 9} \%$ yield from BnMgCl<smiles>C=CCc1ccc(C)cc1</smiles>

5c, $79 \%$ yield<smiles>C=CC[14CH2]C=C</smiles>

$5 \mathrm{~g}, \mathbf{9 4 \%}$ yield<smiles>[R7]CC([R])=C</smiles>

5<smiles>C=CCc1ccc(N(C)C)cc1</smiles>

$5 \mathrm{~d}, 64 \%$ yield<smiles>C=C(CC(=C)c1ccccc1)c1ccccc1</smiles><smiles>C=CCCCC(=C)c1ccccc1</smiles>

5 j, $97 \%$ yield<smiles>C=C(CCC)C(C)(C)C</smiles>

$5 k, 99 \%$ yield<smiles>C=CCCCC1OCCCO1</smiles>

5h, $79 \%$ yield

$5 i, 75 \%$ yield

\footnotetext{
${ }^{a}$ Reaction conditions: Terminal alkene $\left(\mathrm{R}=\mathrm{H}: 1\right.$ atm balloon; $\mathrm{R}=\mathrm{Ph}, t$ - $\mathrm{Bu}: 0.25 \mathrm{mmol}, 1$ equiv), $\left(\mathrm{PhSO}_{2} \mathrm{~N}\right) 2 \mathrm{~S}(0.30 \mathrm{mmol}, 1.2 \mathrm{equiv}), \mathrm{CH}_{2} \mathrm{Cl}_{2}$ $(0.5 \mathrm{~mL}, 0.5 \mathrm{M}), 0{ }^{\circ} \mathrm{C}, 40 \mathrm{~min}$; then $\mathrm{CH}_{2} \mathrm{Cl}_{2}\left(0.05 \mathrm{M}\right.$ by dilution), $\mathrm{CuCN}(10 \mathrm{~mol} \%), \mathrm{R}^{1} \mathrm{MgBr}$ (4 equiv), 0 to $23{ }^{\circ} \mathrm{C}, 4 \mathrm{~h}$.
} 
Table 3.

Scope of Grignard Reagents for the Branch-Selective Allylic Alkylation ${ }^{d}$

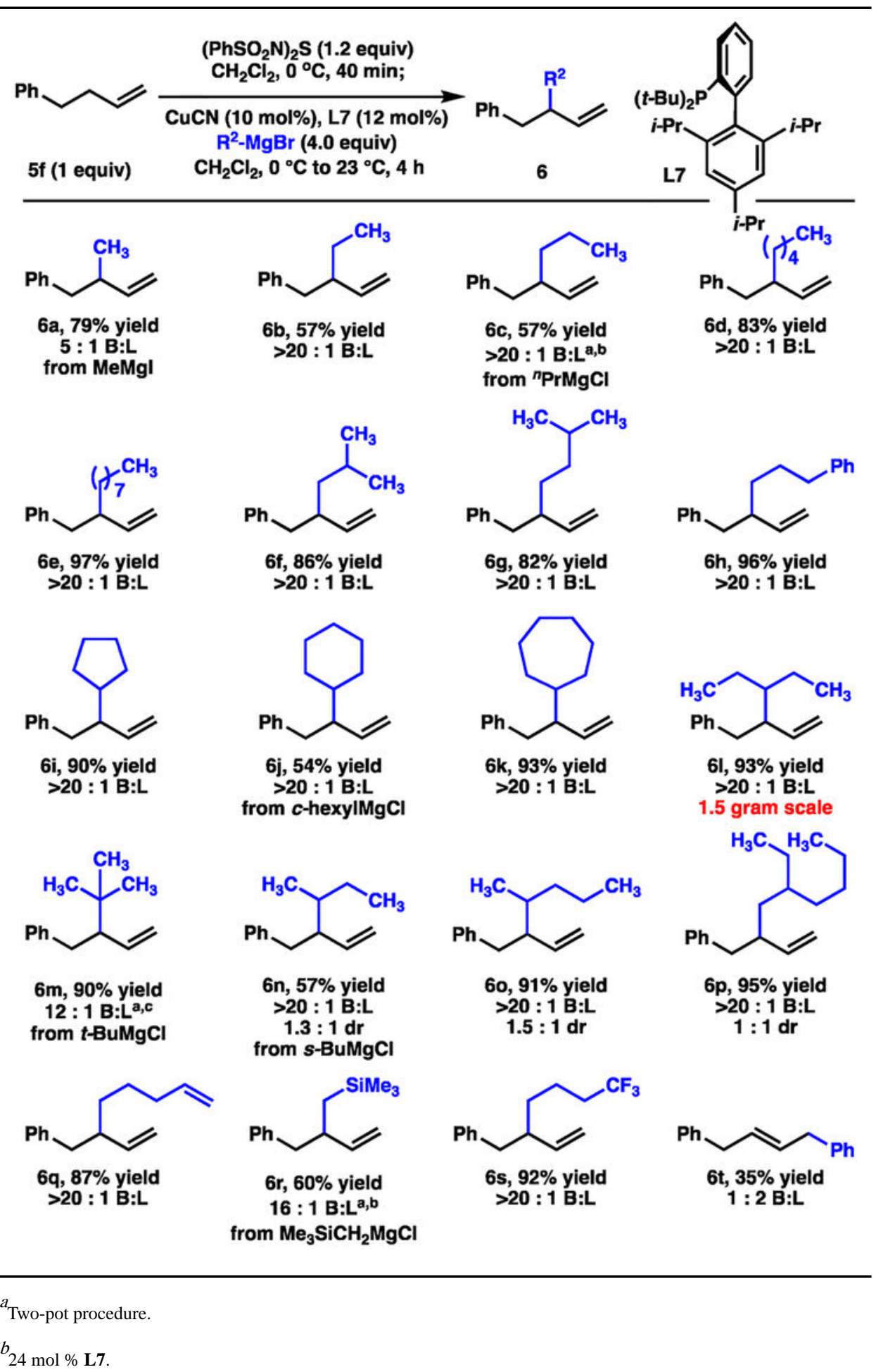

J Am Chem Soc. Author manuscript; available in PMC 2020 May 12. 


\section{${ }^{c}$ No $\mathbf{L} 7$.}

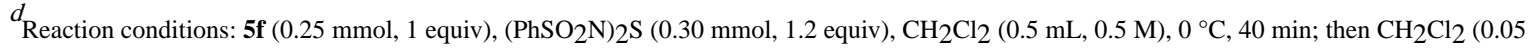

$\mathrm{M}$ by dilution), $\mathrm{CuCN}(10 \mathrm{~mol} \%), \mathbf{L 7}(12 \mathrm{~mol} \%), \mathrm{R}^{2} \mathrm{MgBr}$ (4 equiv), 0 to $23{ }^{\circ} \mathrm{C}, 4 \mathrm{~h}$. B:L is branched:linear allylic alkylation products. 
Table 4.

Scope of Functionalized Alkenes for the Branch-Selective Allylic Alkylation ${ }^{b}$

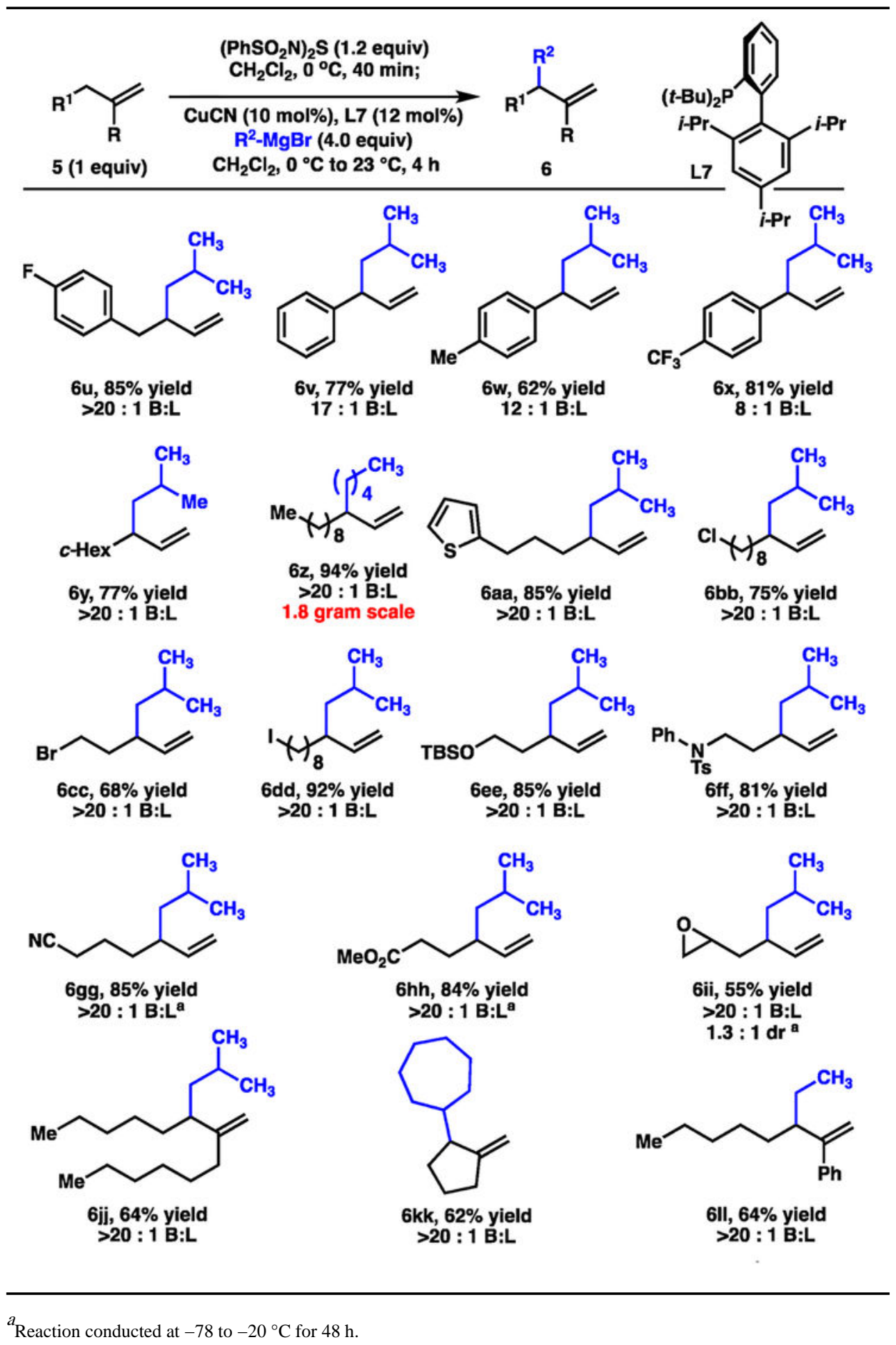

J Am Chem Soc. Author manuscript; available in PMC 2020 May 12. 


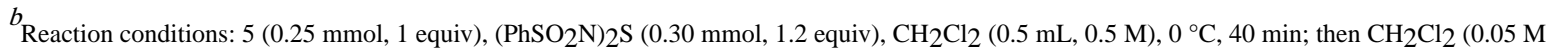
by dilution), $\mathrm{CuCN}(10 \mathrm{~mol} \%), \mathbf{L 7}(12 \mathrm{~mol} \%), \mathrm{R}^{2} \mathrm{MgBr}$ (4 equiv), 0 to $23{ }^{\circ} \mathrm{C}, 4 \mathrm{~h}$. B:L is branched:linear allylic alkylation products. 
Table 5.

Synthesis of Fully Substituted Allylic Carbon Centers from Tertiary Allylic Alkenes ${ }^{a}$

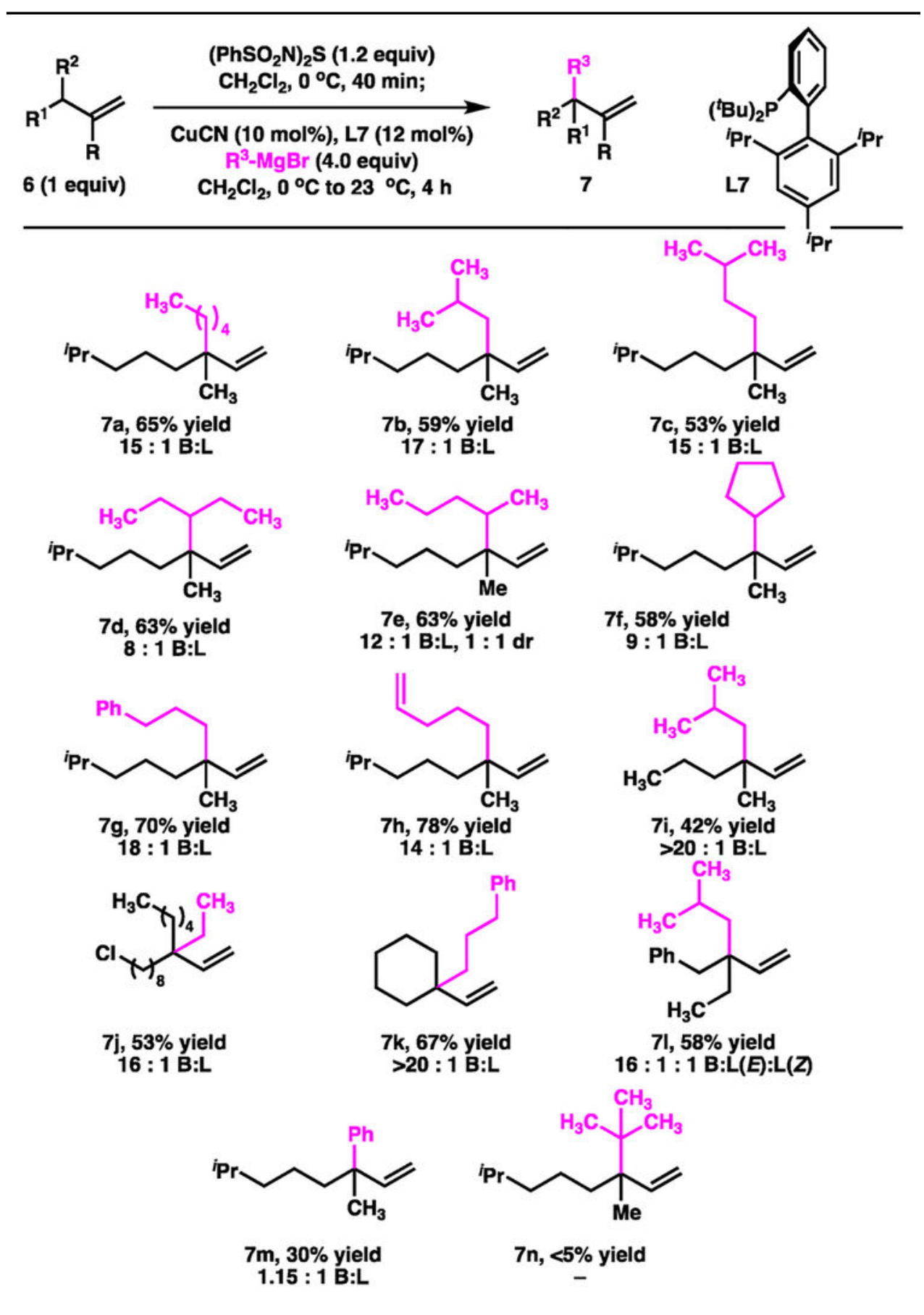

${ }^{a}$ Reaction conditions: $6\left(0.25 \mathrm{mmol}, 1\right.$ equiv), $\left(\mathrm{PhSO}_{2} \mathrm{~N}\right) 2 \mathrm{~S}\left(0.30 \mathrm{mmol}, 1.2\right.$ equiv), $\mathrm{CH}_{2} \mathrm{Cl}_{2}(0.5 \mathrm{~mL}, 0.5 \mathrm{M}), 0{ }^{\circ} \mathrm{C}, 40 \mathrm{~min}$; then $\mathrm{CH}_{2} \mathrm{Cl}_{2}(0.05 \mathrm{M}$ by dilution), $\mathrm{CuCN}(10 \mathrm{~mol} \%), \mathbf{L 7}(12 \mathrm{~mol} \%), \mathrm{R}^{3} \mathrm{MgBr}$ (4 equiv), 0 to $23^{\circ} \mathrm{C}, 4 \mathrm{~h}$. B:L is branched:linear allylic alkylation products. 
Table 6.

Controllable and Sequential Allylic Alkylation of Propylene ${ }^{a}$

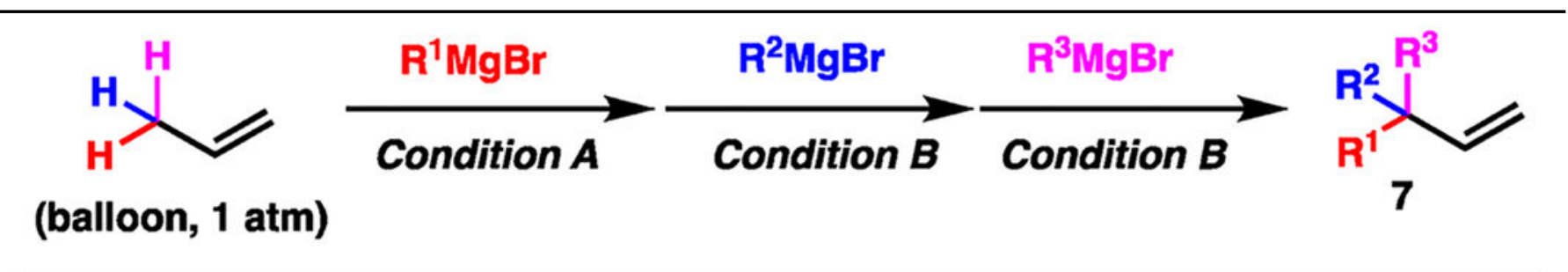

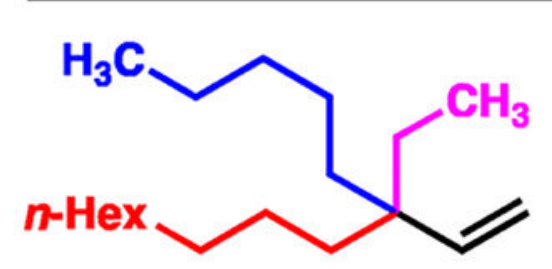<smiles>C=CC(CC)(CC)CCC1OCCCO1</smiles>

7p, 76\%; 90\%; 52\% $>20: 1$ B:L<smiles>C=CC(CC)(CCCCC)CCCc1ccccc1</smiles>

\section{7r, 93\%; 90\%; 60\%} $>20: 1$ B:L

7s, $93 \%$; $90 \%$; $74 \%$ $>20: 1$ B:L

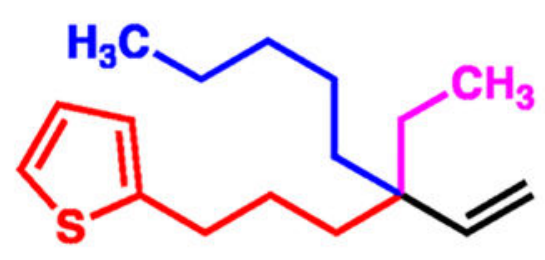

7q, $76 \%$; $87 \%$; $51 \%$ $>20: 1 \mathrm{~B}: \mathrm{L}$

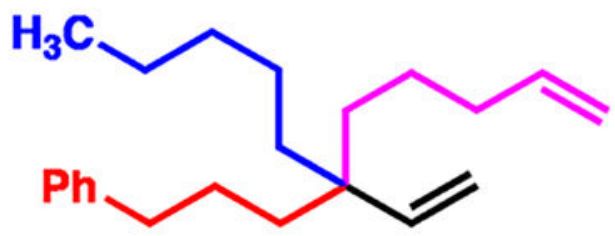

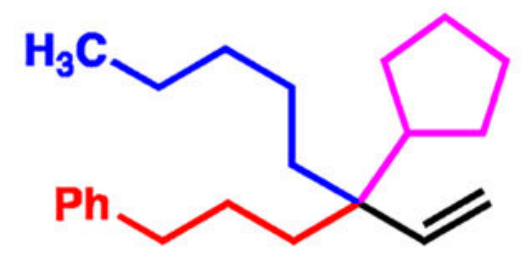

7t, 93\%; 90\%; 62\% 7:1 B:L

${ }^{a}$ Condition A: propylene (balloon, 1 atm), $\left(\mathrm{PhSO}_{2} \mathrm{~N}\right) 2 \mathrm{~S}$ (1 equiv), $\mathrm{CuCN}(10 \mathrm{~mol} \%), \mathrm{CH}_{2} \mathrm{Cl}_{2}, 0{ }^{\circ} \mathrm{C}, 40 \mathrm{~min} ; \mathrm{RMgBr}\left(4\right.$ equiv), $\mathrm{CH}_{2} \mathrm{Cl}_{2}, 0$ to 23 ${ }^{\circ} \mathrm{C}, 4$ h. Condition B: alkene (1 equiv), $\left(\mathrm{PhSO}_{2} \mathrm{~N}\right) 2 \mathrm{~S}$ (1.2 equiv), $\mathrm{CuCN}(10 \mathrm{~mol} \%), \mathbf{L} 7(12 \mathrm{~mol} \%), \mathrm{CH}_{2} \mathrm{Cl}_{2}, 0{ }^{\circ} \mathrm{C}, 40 \mathrm{~min} ; \mathrm{RMgBr}(4 \mathrm{equiv})$, $\mathrm{CH}_{2} \mathrm{Cl}_{2}, 0$ to $23{ }^{\circ} \mathrm{C}, 4 \mathrm{~h}$. B:L ratios refer to the overall branched:linear allylic alkylation product ratios after the third alkylation step. 
Table 7.

Optimization of Catalytic Enantioselective Branch-Selective Allylic Alkylation ${ }^{f}$

\begin{tabular}{|c|c|c|c|c|c|}
\hline \multirow{2}{*}{1 (2 equiv) } & \multicolumn{3}{|c|}{ 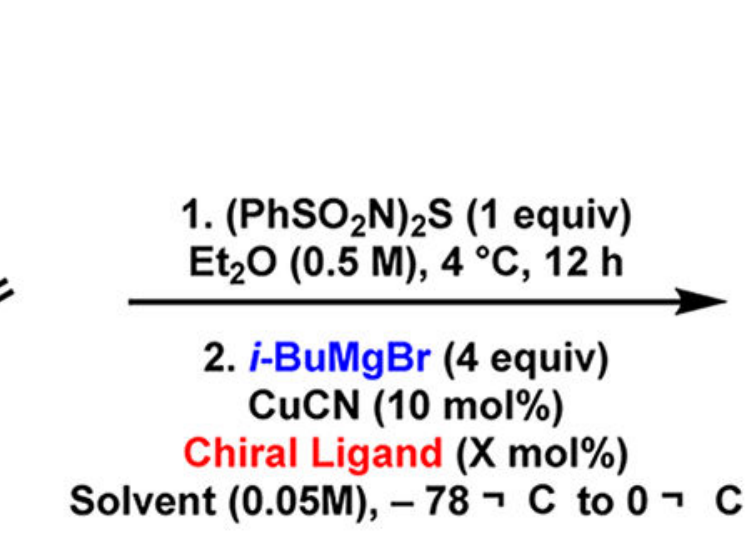 } & $\mathrm{Ph}$ & \\
\hline & Chiral liqand ${ }^{a}$ & solvent & yield $^{b}$ & $3: 4^{c}$ & er ${ }^{d}$ \\
\hline 1 & L8 & $\mathrm{CH}_{2} \mathrm{Cl}_{2}$ & $47 \%$ & $18: 1$ & $50.5: 49.5$ \\
\hline 2 & L9 & $\mathrm{CH}_{2} \mathrm{Cl}_{2}$ & $63 \%$ & $>20: 1$ & $51.5: 48.5$ \\
\hline 3 & L10 & $\mathrm{CH}_{2} \mathrm{Cl}_{2}$ & $25 \%$ & $>20: 1$ & $50.5: 49.5$ \\
\hline 4 & L11 & $\mathrm{CH}_{2} \mathrm{Cl}_{2}$ & $64 \%$ & $>20: 1$ & $50: 50$ \\
\hline 5 & L12 & $\mathrm{CH}_{2} \mathrm{Cl}_{2}$ & $39 \%$ & $8: 1$ & $51.5: 48.5$ \\
\hline 6 & L13 & $\mathrm{CH}_{2} \mathrm{Cl}_{2}$ & $58 \%$ & $>20: 1$ & $49: 51$ \\
\hline 7 & L14 & $\mathrm{CH}_{2} \mathrm{Cl}_{2}$ & $69 \%$ & $>20: 1$ & $48.5: 51.5$ \\
\hline 8 & L15 & $\mathrm{CH}_{2} \mathrm{Cl}_{2}$ & $58 \%$ & $>20: 1$ & $51: 49$ \\
\hline 9 & L16 & $\mathrm{CH}_{2} \mathrm{Cl}_{2}$ & $86 \%$ & $4: 1$ & $53.5: 46.5$ \\
\hline 10 & L17 & $\mathrm{CH}_{2} \mathrm{Cl}_{2}$ & $41 \%$ & $>20: 1$ & $49.5: 50.5$ \\
\hline 11 & L18 & $\mathrm{CH}_{2} \mathrm{Cl}_{2}$ & $82 \%$ & $>20: 1$ & $78: 22$ \\
\hline 12 & L18 & $t$-BuOMe & $48 \%$ & $15: 1$ & $64: 36$ \\
\hline 13 & L18 & $\mathrm{PhMe}$ & $91 \%$ & $>20: 1$ & $84: 16$ \\
\hline $14^{e}$ & L18 & $\mathrm{PhMe}$ & $86 \%$ & $>20: 1$ & $94: 6$ \\
\hline
\end{tabular}




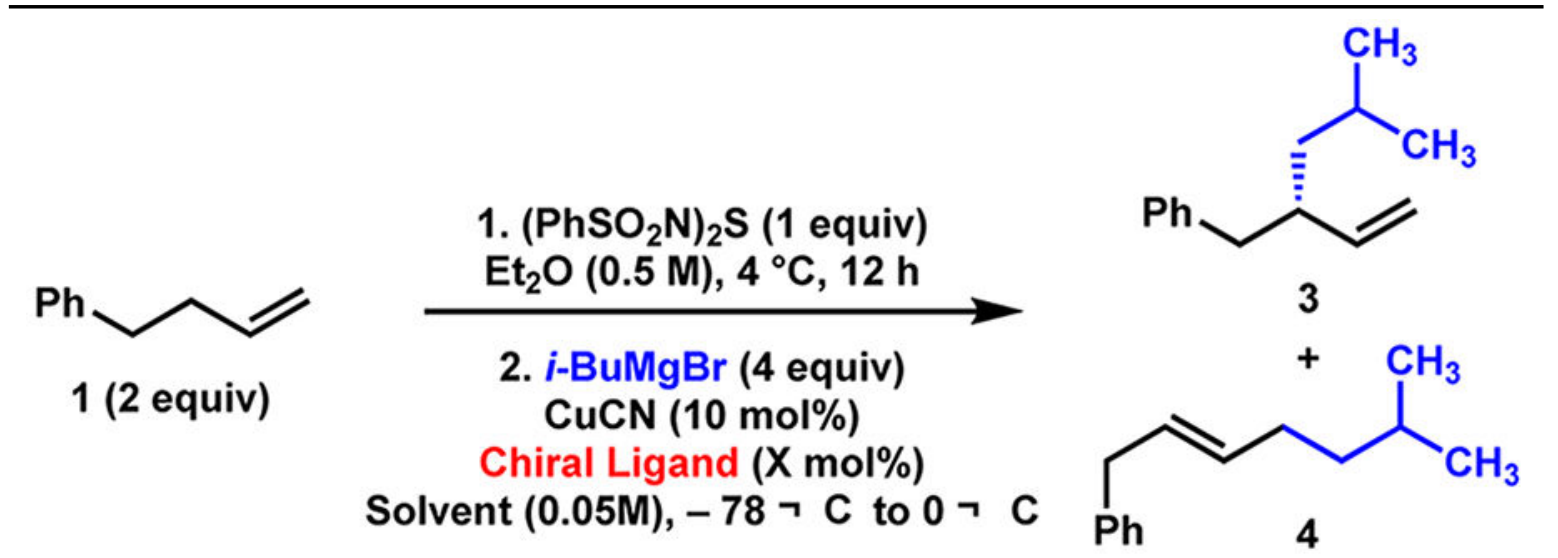

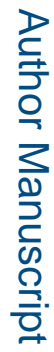

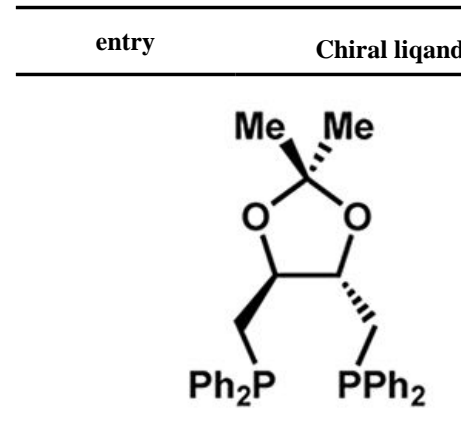

L8<smiles>c1ccc(-c2ccc3ccccc3c2-c2c(-c3ccccc3)ccc3ccccc23)cc1</smiles>

L9<smiles>Pc1cccc(P)c1-c1cccc(P)c1-c1ccccc1</smiles>

L10

ᄅ<smiles>O=C(N[C@H]1CCCC[C@@H]1NC(=O)c1c(P)ccc2ccccc12)c1c(P)ccc2ccccc12</smiles>

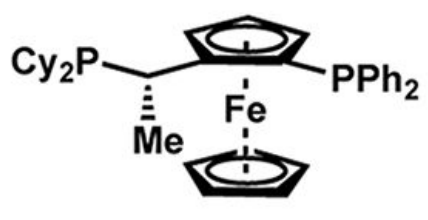

를

L11

L12<smiles>c1ccc(P(c2ccccc2)c2ccc3ccccc3c2-c2nccc3ccccc23)cc1</smiles>

L13<smiles>C[C@H](c1ccccc1)C(C(c1ccccc1)c1ccccc1)p1oc2ccc3ccccc3c2c2c(ccc3ccccc32)o1</smiles>

L14<smiles>c1ccc(CP(Cc2cccc3c2[C@@]32CCc3ccccc32)OP(c2ccccc2)c2ccccc2)cc1</smiles>

L15

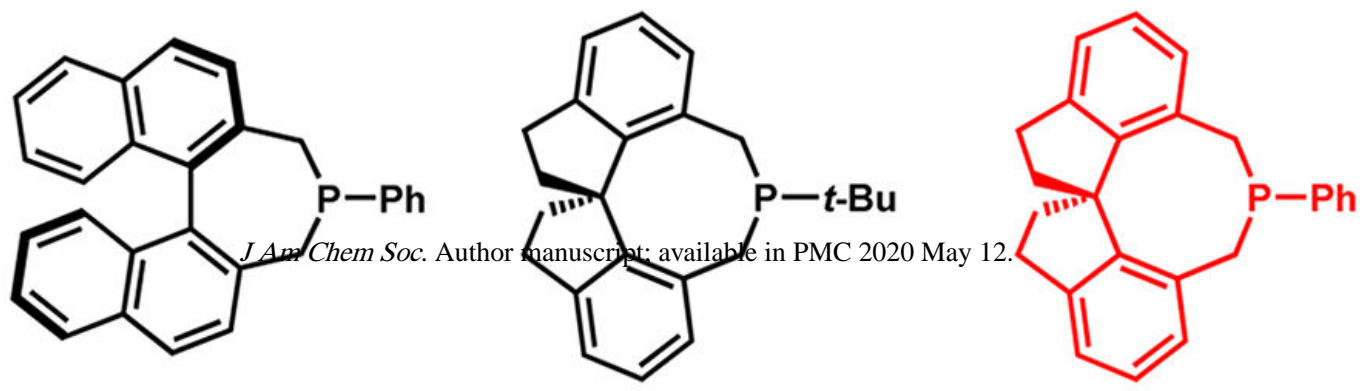


${ }_{24} \mathrm{~mol} \%$ of monodentate ligand, $12 \mathrm{~mol} \%$ of bidentate ligand.

$b_{\text {Isolated yield. }}$

${ }^{c}$ Determined by ${ }^{1} \mathrm{H}$ NMR analysis.

${ }^{d}$ Determined by chiral HPLC analysis of derivative.

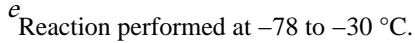

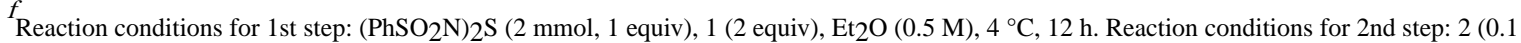
mmol, 1 equiv), solvent ( $0.05 \mathrm{M}$ by dilution), $\mathrm{CuCN}(10 \mathrm{~mol} \%)$, chiral ligand (12 or $24 \mathrm{~mol} \%), i-\operatorname{BuMgBr}\left(2 \mathrm{M}\right.$ in Et2 $\mathrm{O}, 4$ equiv), -78 to $0{ }^{\circ} \mathrm{C}$. 
Table 8.

Scope of Catalytic Enantioselective Branch-Selective Allylic Alkylation ${ }^{b}$

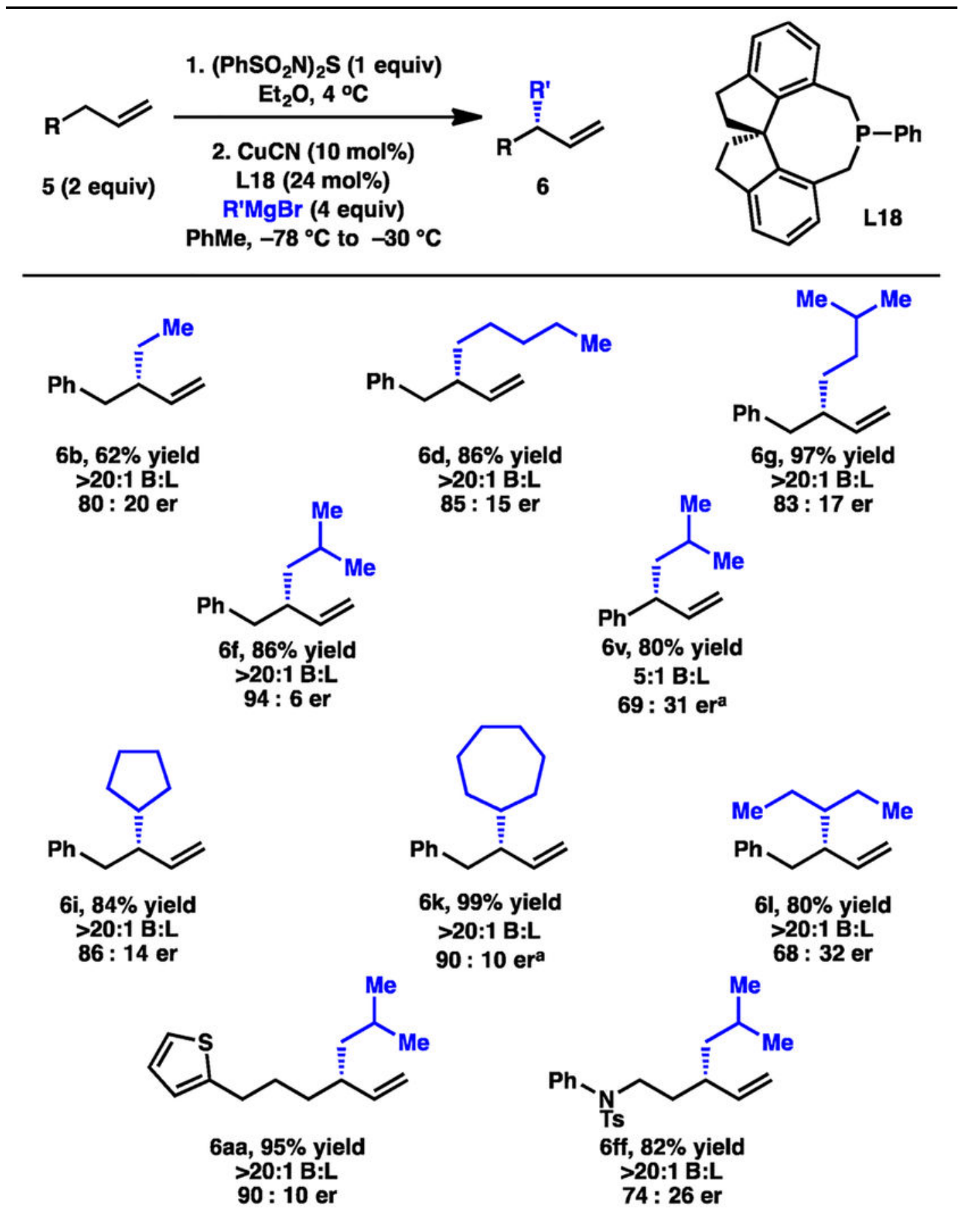

${ }^{a} \mathrm{PhCF}_{3}$ as a solvent, reaction performed at -78 to $0{ }^{\circ} \mathrm{C}$ 


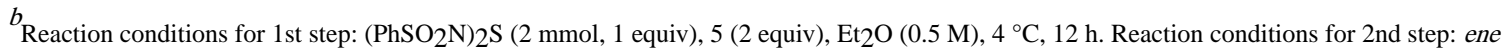
adduct (0.1 mmol, 1 equiv), $\mathrm{PhMe}$ ( $0.05 \mathrm{M}$ by dilution), $\mathrm{CuCN}$ (10 mol \%), $\mathbf{L 1 8}(24 \mathrm{~mol} \%), \mathrm{R}^{\prime} \mathrm{MgBr}$ (4 equiv), -78 to $-30{ }^{\circ} \mathrm{C}$. B: $\mathrm{L}$ is branched:linear allylic alkylation products. 